\title{
ESEF 65 anos: entre memórias e histórias
}

Silvana V. Goellner, Karine Dalsin, Luanda dos S. Dutra, Giovanni E. Frizzo, Johanna C. von Muhlen, Camile S. Romero, Ana Paula Duarte, Heloisa P. Carmona, Leila C. Mattos ${ }^{*}$

\begin{abstract}
Resumo: Esse texto faz parte do projeto de pesquisa intitulado "Garimpando Memórias" desenvolvido pela equipe do Centro de Memória do Esporte da ESEFUFRGS. Através da perspectiva teórico-metodológica da história oral objetiva narrar alguns fragmentos da história dos 65 anos da Escola de Educação Física, completados no mês de maio de 2005. Para tanto foram realizadas 48 entrevistas com professores, servidores técnicos- administrativos e acadêmicos que ainda estão atuando na Escola ou que já fizeram parte de seus quadros. Ao privilegiar a memória dos entrevistados esse texto se constrói não como uma história oficial da instituição mas, fundamentalmente, como o relato de algumas memórias que, agrupadas em temas, explicitam um pouco da vida da ESEF desde sua criação até os dias atuais.
\end{abstract}

Palavras-chave: Escola de Educação Física, memória, história.

O Governo Federal, no ano da graça de Nosso Senhor Jesus Cristo de 1939 pelo Decreto $\mathrm{n}^{\circ} 1.212$, passou a exigir formação profissional específica para o exercício das profissões de professor de Educação Física, Técnico Desportivo, Médico Especializado Educação Física e Desportos etc. O então Secretário de Educação do Estado do Rio Grande do Sul, Dr. José Pedro Coelho de Souza, atendendo à determinação do Interventor Federal no Rio Grande do Sul, General Oswaldo Cordeiro de Farias, apresenta-lhes, em fins de 1939, a proposta de criação do Departamento Estadual de Educação Física, dele fazendo parte integrante a Escola de Educação Física. Para Diretor do Departamento e da Escola é nomeado, com licença do Ministro da Guerra, o capitão Olavo Amaro da Silveira. O capitão Olavo começa imediatamente a formar um entusiasta grupo de trabalho, cujo núcleo inicial era formado pelo Diretor-Fundador da ESEF e mais os professores: Waldir Calvet Echart, Frederico Guilherme Gaelzer, João Gomes

* Este texto se origina de uma pesquisa desenvolvida coletivamente ao longo de um ano. Os autores participaram de todas as suas etapas, a saber: realização e processamento das entrevistas, discussão das entrevistas, escolha dos temas privilegiados para compor o texto e a escrita do mesmo.

Movimento, Porto Alegre, v. 11, n. 3, p. 201-218, setembro/dezembro de 2005 
Moreira Filho e Max Herbert Hanke, aos quais logo se juntaram outros idealistas da educação física. Trabalhando com ardor inexcedível, o grupo vence rapidamente as dificuldades iniciais, e já nos primeiros meses de 1940, a Escola apresenta condições para começar suas atividades. E, assim, embora sem a verificação prévia do Ministério da Educação, o interventor Federal determina o início das aulas, o que é feito em sessão solene no dia 06 de maio de 1940, sendo a benção da Igreja dada pelo reverendíssimo padre Arthur Wickert (GUTIERREZ, 1971).

Considerado como um dos únicos registros sobre a criação da ESEF-UFRGS, esse documento escrito pelo professor Washington Gutierrez no ano de 1971 serviu, por muito tempo, para que pudéssemos vislumbrar (ou imaginar) um tempo decorrido há 65 anos. Possibilitou, ainda, que outros trabalhos pudessem olhar o caminho traçado por essa instituição e, assim, a partir de diferentes temáticas e perspectivas teóricas e metodológicas, analisar não apenas sua criação e estruturação mas, sobretudo, diferentes vestígios de sua trajetória.

Entendendo a história não como a realidade sobre algo transcorrido no passado, mas como um discurso sobre o real, esse texto, objetiva narrar fragmentos da história da ESEF a partir da memória de diferentes homens e mulheres que, em diferentes tempos, vivenciaram essa instituição. Não se trata, portanto, de uma narrativa oficial sobre a história da ESEF. O que está reunido nessa pesquisa são pequenos vestígios da memória de alguns de seus sujeitos cujas informações permitiram esboçar as reflexões aqui apresentadas. Nesse sentido, torna-se pertinente ressaltar que, mesmo sendo palavras próximas, História e passado são coisas absolutamente diferentes visto que

o passado e a história não estão unidos um ao outro de tal maneira que se possa ter apenas uma leitura histórica do passado. O passado e a história existem livres um do outro; estão muito distantes entre si no tempo e no espaço. Isto porque o mesmo objeto de investigação pode ser interpretado por diferentes práticas discursivas (...) ao mesmo tempo em que, em cada uma destas práticas, há diferentes leituras interpretativas no tempo e no espaço (JENKINS, 2004, p. 24).

Entender a História como uma narrativa ou como um discurso sobre o real pressupõe aceitar que ela está longe de revelar uma suposta verdade acontecida no passado ou se constituir como o próprio passado, como se pensava outrora. Significa perceber que a História tem como meta atingir a verdade do acontecido, mas não como mímesis. Entre aquilo que teve lugar um dia, em um tempo físico já transcorrido e irreversível, e o texto que conta o que aconteceu, há uma mediação" (PESAVENTO, 2003, p. 50). Mediação

Movimento, Porto Alegre, v. 11, n. 3, p. 201-218, setembro/dezembro de 2005 
essa construída também pela memória dos sujeitos que, mesmo sendo guardada por um indivíduo cujas referências são as suas experiências e vivências, está marcada pelo grupo social onde conviveu e se socializou.

Entendemos, portanto, que o caráter social da memória constitui-se em um elemento essencial da formação de sua identidade bem como da percepção que tem de si mesmo e dos outros. Nas palavras de Henry Rousso: "Se o caráter coletivo de toda a memória individual nos parece evidente, o mesmo não se pode dizer da idéia de que existe uma 'memória coletiva', isto é, uma presença e portanto uma representação do passado que sejam compartilhadas nos mesmos termos por toda uma coletividade" (1996, p.95).

Nesse particular, ressaltamos que as memórias aqui narradas, ainda que sejam individuais, revelam, ao mesmo tempo, lembranças coletivas e também interpretações particularizadas. Não podem, portanto, ser tomadas como a "verdade" sobre o que narra: representam a percepção de quem narra ou ainda os significados que atribui ao que é narrado.

Sustentada pelo eixo teórico-metodológico da História Oral essa pesquisa apresenta como fontes primárias depoimentos de pessoas que tiveram e têm significativa contribuição e conhecimento sobre a estruturação ESEF. Toma como referência o trabalho desenvolvido pelo Centro de Documentação de História Contemporânea do Brasil, ligado à Fundação Getúlio Vargas (CPDOC) cuja compreensão acerca da História Oral pode ser assim resumida:

A história oral é um método de pesquisa (histórica, antropológica, sociológica etc.) que privilegia a realização de entrevistas com pessoas que participaram de, ou testemunharam, acontecimentos, conjunturas, visões de mundo, como forma de se aproximar deste objeto de estudo. Como conseqüência, o método de história oral produz fontes de consulta (entrevistas) para outros estudos, podendo ser reunidas em um acervo aberto a pesquisadores. Trata-se de estudar acontecimentos históricos, instituições, grupos sociais, categorias profissionais, etc., à luz de depoimentos de pessoas que deles participaram ou os testemunharam (ALBERTI, 1989, p. 1-2).

Para essa pesquisa foram entrevistados 50 sujeitos entre professores, servidores técnicos-admininstrativos e alunos que ainda estão atuando ou que já fizeram parte dos quadros da Escola. Estas entrevistas abrangeram desde os anos 30 do século XX até a atualidade objetivando compor um conjunto de informações que oferecesse possibilidades de analisar a trajetória da ESEF desde seus primórdios. Mesmo que muitas dessas entrevistas não tenham sido citadas no corpo do texto, é necessário evidenciar que foram funda-

Movimento, Porto Alegre, v. 11, n. 3, p. 201-218, setembro/dezembro de 2005 
mentais para sua estruturação pois permitiram aos pesquisadores conhecer diferentes olhares sobre um mesmo tema. ${ }^{1}$

Vale lembrar que assim como a entrevista está intimamente relacionada à memória, seu processamento articula, simultaneamente, pesquisa e documentação na medida em que permite, também, a produção de um documento histórico. Daí sua riqueza pois “a evidência oral, transformando os 'objetos' de estudo em 'sujeitos', contribui para uma história que não só é mais rica, mais viva e mais comovente, mas também mais verdadeira" (THOMPSON, 1992, p. 136). Verdadeiro, entendido nesse contexto, não no sentido de que o que está sendo relatado efetivamente aconteceu assim, mas de que há ali uma vida a ser exposta a partir de quem a viveu.

Razão pela qual, para a realização de uma pesquisa como esta, muitos foram os cuidados tomados desde o seu início objetivando, em primeiro lugar, respeitar o sujeito entrevistado sem alterar o significado do que pensa, relata e conta. Para tanto, utilizamos os seguintes procedimentos metodológicos:

a)Identificação das pessoas a serem entrevistadas;

b)Elaboração de roteiros para cada entrevista - este procedimento foram realizados depois de já termos algumas informações sobre o entrevistado e sua relação com o tema da entrevista.

c) Realização da entrevista;

d)Processamento da entrevista - caracteriza-se como todo processo envolvido na passagem do depoimento da forma oral para a escrita, incluindo as etapas de transcrição, conferência de fidelidade, copidesque e leitura final;

e)Assinatura, por parte do entrevistado, de um documento concedendo ao Centro de Memória do Esporte do Esporte da Escola de Educação Física a propriedade e os direitos autorais do depoimento de caráter histórico e documental;

f) Catalogação da entrevista conforme orientações específicas visando a organização do acervo de memórias;

g)Disponibilização para consulta via meios computacionais ou in loco.

1 Todas as entrevistas estão disponibilizadas para consulta no acervo do Centro de Memória do Esporte.

Movimento, Porto Alegre, v. 11, n. 3, p. 201-218, setembro/dezembro de 2005 
Paralelo a realização e processamento das entrevistas foram consultadas várias outras fontes como, por exemplo, atas e registros oficiais da Escola e reportagens em jornais e revistas. A partir do diálogo estabelecido entre as diferentes fontes, privilegiando como já foi mencionado, os depoimentos orais, elegemos quatro temas para desenvolver nesse texto, a saber: "A comunidade esefiana e o pertencimento familiar"; "As mulheres na ESEF: visibilidades conquistadas"; "Resistências Estudantis: movimento em constante construção" e "Fatos pitorescos: detalhes do cotidiano".

\section{A comunidade esefiana e o pertencimento familiar}

Desde sua criação diferentes pessoas com suas diferentes personalidades compartilharam não apenas o mesmo espaço físico, mas também as mesmas rotinas, tarefas e, digamos assim, vários sentimentos em comum. Muitas entrevistas mencionaram ter sido a ESEF o espaço que permitiu a emergência de grandes amizades, amores, casamentos, desavenças, tensões e rompimentos. Nas primeiras décadas de sua existência aparecem vários depoimentos que mencionam o sentimento de união entre os "esefianos", em especial porque muitos dos seus alunos provinham de outras cidades do estado sendo a Escola representada como um local de aconchego, de referência identitária e de pertencimento. Para a ex-aluna Eneida Feix:

Era uma coisa muito linda ser da ESEF. Tu enchias a boca: eu estudo na ESEF/ UFRGS, era uma coisa um orgulho. A gente fazia o desfile da Semana da Pátria, ia para o desfile apresentava a ESEF. Os colegas também. Eu encontro eles é aquela emoção assim sabe. Aquela coisa de irmandade mesmo. Muito legal! Muito legal! Ficam marcas para sempre, a gente se encontra e é aquele carinho, aquela ternura assim (FEIX, 2005, p.7)

O termo "família", seguidamente foi mencionado nos depoimentos, em grande parte deles quando o assunto abordado tematizava as relações pessoais dos entrevistados. O ex-aluno Walter de Souza, ao rememorar sua vivência na Escola no final da década de 50, faz a seguinte afirmação: “A relação com os funcionários eram as melhores possíveis. Aquilo era uma família, parecia uma família, funcionários, professores e alunos. Era uma família" (2005, p.05).

Essa aproximação afetiva proporcionava, para além de sólidas amizades, outras formas de relacionamento entre os alunos. Muitos foram os casamentos, os namoros e as relações amorosas. Nelson Saul narra com entusiasmo o princípio de namoro que resultou no seu casamento, em 1956, com a também aluna Guisela Strauss.

Movimento, Porto Alegre, v. 11, n. 3, p. 201-218, setembro/dezembro de 2005 
Conta o entrevistado que naquele tempo (anos 50), as regras de comportamento eram muito rígidas e poucas aproximações havia entre os alunos e as alunas, inclusive porque todas as disciplinas que envolviam exercitação corporal eram separadas por sexo. Ainda assim, diz Nelson, "nós tínhamos os recreios e as excursões... E numa excursão em Cachoeira foi onde deu o 'tchan' E aí continuamos, né. Nos conhecemos na Escola começamos a namorar e, quando nós nos formamos, em 1954, nós noivamos e casamos em 1956" (SAUL, 2005, p.3).

Assim como Nelson e Guisela vários outros casais formaram-se e dissolveram-se nesses 65 anos e vários descendentes desses casais também tomaram a ESEF como o espaço de sua formação profissional. Circulando pelas suas dependências desde crianças foram inspirados seja pela família, seja pela instituição e fizeram da Educação Física sua profissão passando, então, a integrar o que comumente foi mencionado pelos entrevistados como "a comunidade esfiana".

Walter de Souza relata que sua tia, Marina Martins de Souza e sua mãe, Mary Higia Traub de Souza, por muito tempo foram funcionárias da Escola. Lembra que "desde os seis, sete, oito anos de idade eu já freqüentava a ESEF como visitante, quando naquela oportunidade a ESEF funcionava nas dependências do Esporte Clube Cruzeiro, onde atualmente está o Cemitério João XXIII" (2005, p. 1). A oportunidade de "crescer" na ESEF despertou no entrevistado a vontade de lá estudar.

Assim como Walter, a ex-aluna Eneida Feix, graduada em 1978, afirma que sua paixão pela Escola iniciou por influência de familiares que fizeram parte das primeiras turmas da ESEF: "Minha mãe se formou em Educação Física em 1944 e minhas duas tias, Vargas Lenenh e Valda Vargas Lehnen, em 1942" (2005, p.8).

No entanto não foram apenas romances, amores e amizades que, nesses anos todos, circularam pelos espaços da ESEF. Tensões, desavenças, disputas políticas, discórdias e desafetos também retrataram as relações entre os integrantes dessa "família". Uma das desavenças mencionadas por alguns entrevistados se deu em função da criação do Laboratório de Pesquisa do Exercício (LAPEX), na década de 70. A primeira disputa se travou em função da sua própria instalação que, segundo Henrique Licht, causou certos desassossegos entre diferentes sujeitos que compunham o quadro diretivo da ESEF, fundamentalmente, porque demandava uma reestruturação dos seus espaços físicos. Nas suas palavras:

Movimento, Porto Alegre, v. 11, n. 3, p. 201-218, setembro/dezembro de 2005 
Inclusive quando nós estávamos iniciando as obras lá veio o problema com o Eduardo De Rose sempre sonhador querendo criar o LAPEX e sem área para ser utilizada. Então nós tivemos que conseguir uma casa que instalamos provisoriamente e foi muito criticada... Para que nós pudéssemos tirar o zelador da Escola que morava lá e liberar as dependências para instalar inicialmente o LAPEX (LICHT, 2005, p.4).

Não apenas a criação do LAPEX se deu contemplando diversos desafios mas o acesso as suas dependências, já nos seus primeiros momentos, causava discordâncias. Segundo Eduardo Henrique de Rose, seu primeiro diretor:

no meu tempo a proibição era da Escola, de não deixar o pessoal do LAPEX entrar e, em geral, não favorecer que os alunos fossem ao LAPEX, ou se tornassem monitores do LAPEX. Então isso, evidentemente, tornou o LAPEX um pouco fechado ou blindado, mas depois de 85, quando o LAPEX passou a integrar a Escola, com professores do LAPEX sendo professores da Escola, isso tudo terminou (2005, p.11).

Muitas das tensões que apareceram na trajetória da ESEF podem ser relacionadas aos campos de intervenção profissional que conduziram a Direção da Escola: os militares, posteriormente os médicos e os professores de Educação Física e, depois dos anos oitenta, entre os próprios professores de Educação Física, muitos deles formados na própria ESEF. Pequenas ou grandes, visíveis ou invisibilizadas, essas tensões fazem parte da constituição da Escola mesmo que nos depoimentos dos entrevistados, de uma forma geral, foram sempre minimizadas em função das conquistas, dos desafios enfrentados, dos laços construídos. O médico Henrique Licht, no seu depoimento, exemplifica muito bem essa afirmação quando declara:

E se tiver algum que, evidente, numa comunidade tão grande feito essa algum discordante coisa e tal, não chega nem a prejudicar nada. A imagem que a gente faz é de um ambiente muito bom e fiquei muito satisfeito agora que tenho ido mais seguidamente na ESEF, na minha ESEF com o ambiente que eu encontrei (2005, p.7).

Estes sentimentos, entre tantos outros, transparecem nas entrevistas realizadas e, de certa maneira, são representados pelos narradores como um dos pilares que, nesses 65 anos sustentou a ESEF. Pertencer à Escola, fazer parte dessa "família" demonstra não apenas um sentimento de orgulho da própria instituição mas, sobretudo, de fazer parte dela. Ou melhor, de estar inscrito na sua história, seja lá em que época for, independente, inclusive, dos desencantos vividos.

Movimento, Porto Alegre, v. 11, n. 3, p. 201-218, setembro/dezembro de 2005 


\section{As mulheres na ESEF: visibilidades conquistadas}

Não dúvidas de que a fundação da ESEF incentivou muitas mulheres para a adesão e permanência no campo das práticas corporais esportivas. A participação feminina em um espaço tido como de domínio masculino como, por exemplo, o esportivo, decorreu, em certa medida, da inserção das mulheres como estudantes nos cursos oferecidos pela Escola. Através de vários depoimentos foi possível observar que, nas décadas de 40, 50 e 60, muitas das atletas que participavam dos clubes da cidade, eram alunas da ESEF, tornandose, posteriormente, professoras em escolas públicas e privadas.

Nos seus primeiros anos de existência a Escola foi procurada, predominantemente, por moças que buscavam sua qualificação como professoras. Na primeira turma matricularam-se 124 discentes, sendo 26 do sexo masculino e 98 do sexo feminino - estas, na sua maioria, eram professoras em exercício, fato que se confirmou como tendência nas turmas seguintes. Olga Valéria Kroeff Echart, aluna da primeira turma e posteriormente professora da ESEF, relata: "na minha época, quando eu tirei a Escola de Educação Física em 1940, vamos dizer, nós éramos cinco turmas de mulheres e quatro turmas masculinas eu acho. E sempre foi assim, nunca mulher menos" (2004, p.3).

No momento da sua fundação apenas duas mulheres compunham o quadro docente da Escola, situação essa que se modificou a partir da formatura da primeira turma onde algumas alunas foram convidadas para ministrar as disciplinas de esportes para as moças uma vez que, nesse período, as aulas denominadas como "práticas", ou seja, que envolviam exercitação física, eram separadas por sexo onde as mulheres ministravam aulas para as alunas e os homens para os alunos.

Nos primeiros tempos da Escola, a participação das moças em diferentes modalidades esportivas, dentro e fora das suas dependências não era, ainda, uma prática muito incentivada e, muitas vezes, nem mesmo aceita pela família das atletas e/ou alunas da ESEF. Aluna, na década de 50, Marlene César Richter narra:

Inclusive quando eu fui fazer vestibular de Educação Física eu tive que fazer escondido, eu tive que fazer a segunda chamada porque minha mãe achava que não era bonito, não era elegante uma moça fazer Educação Física. Ela achava que uma moça era para ter outra profissão, mais feminina e tal, no que... Na linguagem dela... E eu realmente eu não tive incentivo da minha família não. Mas depois que eu me formei aí eles entenderam, né! Me deram apoio e tudo, mas para entrar não tive não (2003, p. 4).

Movimento, Porto Alegre, v. 11, n. 3, p. 201-218, setembro/dezembro de 2005 
Da mesma forma Diná Petenuzzo Santiago, atual professora da Escola, relata o conflito que presenciou quando sua irmã, Diva Santiago Corrêa, manifestou à família o desejo de ingressar na ESEF: “Aí minha mãe disse: 'Não tu não vais fazer! Faculdade de Educação Física? Nem pensar! Isso é coisa para homem, tu não vais!"' (2002, p. 3).

Nesse tempo existiam várias restrições para as mulheres, em especial quando relacionadas a sua visibilidade no espaço público. O esporte, considerado como um campo de hegemonia masculina era, não raras vezes, identificado como prejudicial ao corpo e ao comportamento femininos. Um atenuante dessa representação encontrou respaldo no discurso médico desse período que identificava nas atividades físicas uma forma de fortalecer o corpo feminino. Ao mesmo tempo, esse mesmo discurso foi aquele que lhe possibilitou uma série de limitações para as próprias mulheres. Na entrevista de Olga Echart aparece essa tensão:

Os médicos, geralmente os médicos, falavam disso, que a natureza da mulher não permitia, por exemplo, era muito prejudicial para a mulher receber bola no peito, o futsal também. (...) O outro problema era, por exemplo, lutas, era a mulher, as lutas... Eles não achavam que era, que não poderia ter lutas porque a mulher tinha sido preparada para, naquela época em 41 , para ser mãe. Então isso os médicos achavam, assim, horrível porque que a mulher iria se deformar para lutar, quer dizer não foi tanto a proibição por proibir. É porque achavam que isso não estava de acordo com o corpo da mulher que era preparada para outra função $(2004$, p. 5).

Estruturado tendo como referência fundamental o pensamento médico vigente, o currículo inicial da ESEF apresentava diferenças bastante evidentes entre as práticas vivenciadas pelas moças e pelos rapazes, situação essa que se alterou apenas a partir do final dos anos 80. A atual professora da Escola, Helena Alves D'Azevedo (2005) relata que, no final da década de 1970, quando ainda era aluna, os rapazes não podiam se matricular na disciplina de Ginástica Rítmica Desportiva por ser identificada como eminentemente feminina, da mesma maneira que as moças não freqüentavam disciplinas consideradas masculinas, tais como Esgrima II, Remo e Futebol de Salão. Ainda assim Helena matriculou-se em algumas disciplinas que eram oferecidas somente para os rapazes o que causou algumas confusões não apenas de ordem comportamental como operacional. Diz a entrevistada: "Eram cadeiras masculinas e o computador não fazia discriminação de gênero e eu fiquei matriculada. Foi um problema no curso. Até o pessoal com olho atravessado" (p. 3). A aluna conseguiu autorização dos professores para cursar as disciplinas, exceto a de Futebol de Salão, porém sua participa-

Movimento, Porto Alegre, v. 11, n. 3, p. 201-218, setembro/dezembro de 2005 
ção nas aulas era diferenciada pois os próprios professores visavam resguardá-la de possíveis riscos físicos.

Situações como esta demonstram que, se por um lado a Escola incentivava as moças a praticarem esportes, por outro, as privava das práticas consideradas masculinas, e esta privação apresentava-se como uma forma de protegê-las garantindo, assim, sua saúde física, sua feminilidade e sua honra visto que o universo esportivo, entre os anos 50 e 70, não era muito aconselhado para o que se identificava como sendo " uma moça de boa família".

Quintina Paccini, no seu depoimento narra uma série de preconceitos que existiam nos anos 40 direcionados para a participação das mulheres em profissões mais recomendadas para os homens. Narra também as estratégias que, muitas vezes, recorria para disfarçar ou amenizar discussões e interpretações equivocadas acerca de sua escolha profissional. Vejamos:

$\mathrm{Eu}$, para ser franca, quando comecei a estudar, quando eu estava na Escola, não era vista com bons olhos, tanto que eu tinha um namorado que dizia:

"Ela é atleta de cozinha." E eu depois disso, quando eu namorava um ou dançava eu não... Eu escondia, eu não dizia que era da Educação Física, porque eles achavam que Educação Física era masculina, masculinizava. Então eu escondia isso (2005, p. 4).

Espaço privilegiado a para a visibilidade, o exercício de sociabilidade e a inserção feminina no mercado de trabalho, o curso de Educação Física apresentava-se, também, como um fator de constrangimento para algumas de suas alunas, em especial até meados dos anos 70. Através de uma série de transformações sociais e culturais vividas a partir desse período, pequenas e grandes transgressões tornam-se mais evidentes, não somente no interior da estrutura generificada da ESEF mas na própria sociedade brasileira pautada, a partir de então, por uma série de modificações que promoveram a reconfiguração dos locais sociais atribuídos como naturais a homens e mulheres. Modificações essas que não romperam com efetivamente as desigualdades de gênero, seja no campo das práticas corporais e esportivas, seja fora delas.

\section{Resistências Estudantis: movimento em constante construção}

Além de assistirem às aulas, os estudantes da ESEF sempre buscaram espaços de discussões e representatividade dentro da estrutura da instituição. Por essa razão, no ano posterior a sua criação, mais especificamente, no dia 19 de abril de 1941, foi fundado

Movimento, Porto Alegre, v. 11, n. 3, p. 201-218, setembro/dezembro de 2005 
o Diretório Acadêmico Paulo Hollerbach, inicialmente denominado Centro Acadêmico dos Estudantes de Educação Física cujo órgão diretivo chamava-se Diretório Acadêmico dos Estudantes de Educação Física.

Com uma atuação tímida nos seus primeiros anos de existência, o Diretório Acadêmico começou a intensificar suas atividades na década de 50 e isto se deu em função da estruturação do próprio movimento estudantil no Brasil que originou, em 1957, a criação da UNEEF - União Nacional de Estudantes de Educação Física (KAMINSKI, 2005). Nos anos 60, em especial depois do Golpe Militar de 1964, houve muita repressão às atividades estudantis e o Diretório da ESEF praticamente foi extinto. Segundo depoimento de Mário César Cassel, presidente do Diretório nesse período, o espírito militar vivido pela ESEF desde as suas origens colaborou para a desarticulação do Diretório e essa se efetivou logo após a participação dos seus dirigentes em uma plenária que reuniu diversos outros Diretórios da UFRGS onde foi elaborado um manifesto em prol de João Goulart. Imediatamente após essa reunião a sede do Diretório da ESEF foi arrombada e desapareceram vários materiais cuja sindicância montada pela Direção da ESEF culminou na cassação da gestão do Diretório sendo que sua direção foi assumida, a partir de então, pelos estudantes militares que constituíram a comissão sindicante. ${ }^{2}$

Talvez seja essa uma das razões pelas quais, durante a Ditadura Militar, em especial nos anos 70, o Diretório Acadêmico tenha centrado suas ações na organização de eventos esportivos, na distribuição de uniformes para os estudantes, na preparação de apresentações ginásticas e desfiles comemorativos ao dia 7 de Setembro sem haver muito envolvimento com as mobilizações organizadas pelo movimento estudantil nacional. Mário Brauner, ex-aluno e atual professor da Escola faz hoje uma análise do que era a participação da ESEF naqueles tempos sombrios da sociedade brasileira quando relata: "Eu fico arrepiado quando ouço as histórias dos professores de outros cursos que participaram no tempo da Ditadura e da repressão e que foram excluídos e que depois voltaram... Eu, enquanto isso jogava bola!" (2004, p. 5).

Ainda que muitas tenham sido as histórias de derrotas políticas, ao longo dos 65 anos da ESEF, os estudantes também obtive-

2 Sobre esse tema ler a de conclusão de curso de Leon Kaminski, intitulada "Histó rias do movimento estudantil de Educação Física no Rio Grande do Sul (1956 1964)".

Movimento, Porto Alegre, v. 11, n. 3, p. 201-218, setembro/dezembro de 2005 
ram conquistas como, por exemplo, a luta que travaram em defesa de uma sede própria para a Escola. A mobilização para centralizar a ESEF em um único Campus, foi protagonizada tanto por estudantes como por funcionários e professores, mas essa ação possibilitou uma grande organização por parte dos estudantes que, para além de uma sede para a ESEF, reivindicavam também um espaço físico para o próprio Diretório Acadêmico (DA).

No final da década de 50, os estudantes desencadearam uma série de ações contrárias a Direção da ESEF visto que se sentiam pouco atendidos no que respeitava as suas reivindicações. O foco da disputa se deu em torno da tentativa de afastamento do então Diretor, o professor Frederico Guilherme Gaelzer, no entanto, a pauta de reivindicações era ampla e contemplava uma série de questões que, na ótica dos acadêmicos, eram praticamente desconsideradas. Dentre elas destacavam-se: representação discente no Conselho Técnico Administrativo, administração do percentual destinado ao DA das taxas de matrícula, menos rigor na entrada das aulas de alunos que chegassem atrasados, dispensa e não falta para os alunos que estivessem doentes, reforma regimental, manutenção de horários fixos pra reuniões e assembléias do Diretório, entre outras (OLIMPICO, $\mathrm{N}^{\circ} 2$, ano 2).

O descontentamento dos estudantes para com a Direção da Escola e suas reivindicações foram palco de inúmeras atividades, matérias de jornais, reuniões com o Conselho Técnico Administrativo da Universidade e, inclusive, com o então governador do Estado Ildo Meneghetti, que solicitou aos acadêmicos uma lista tríplice para decidir sobre quem poderia substituir o professor Gaelzer. Para Walter de Souza, presidente do Diretório em 1959:

O governador Ildo Meneghetti terminou me convocando para o Palácio de madrugada, depois dos estudantes terem dado 24 horas para o governo demitir o diretor, senão teriam sido tomadas outras atitudes, até inclusive de nível nacional. O governador acatou, aceitou e, nessa madrugada, fomos solicitados a apresentar uma lista tríplice para escolha do diretor, no Governo do Estado, em que foi escolhido e imediatamente empossado o professor de Cinesiologia na oportunidade, Dr. Rui Gaspar Martins (2004, p.5).

Mesmo que essa seja a versão apresentada pelos estudantes efetivou-se, nesse período, a substituição do Diretor da Escola cujos registros oficiais afirmam ter o mesmo deixado o cargo porque teria se encerrado o período de sua gestão. Segundo Leon Kaminski:

Já a versão oficial que consta nas Atas dos Conselhos é a de que o período do mandato de Gaelzer havia terminado e para definir o seu sucessor foi realizada votação, na Congregação, para eleger os membros da lista tríplice Faziam

Movimento, Porto Alegre, v. 11, n. 3, p. 201-218, setembro/dezembro de 2005 
parte da lista os professores Ruy Gaspar Martins, Valdir Echart e Poli Marcelino Espirito (Ata 69 da Congregação, 13/12/1958). Ruy Gaspar Martins é escolhido pelo Governo do Estado e assume a Direção da Escola no dia 24 de fevereiro de 1959 (KAMINSKI, 2005, p. 23)

Independente das versões adotadas para explicar a substituição do diretor, o que importa é perceber que a movimentação estudantil teve grande repercussão nesse período e também nos anos seguintes. O Jornal Olímpico, produzido pelo Diretório Acadêmico, na sua edição de $1^{\circ}$ de setembro de 1959, traz a seguinte afirmação:

Pegou fogo a ESEF, quando no ano passado, exatamente neste período, desencadeou-se a luta com o nosso então Diretor. Tudo terminou da maneira mais favorável possível para nós, quando tivemos aquela memorável reunião conjunta do Diretório e Conselho Técnico. Mas nós fizemos o mesmo papel daqueles políticos que se esgotaram na luta para serem eleitos e depois de vencerem o duelo eleitoral tornam-se apáticos e nada mais fazem de útil. Tínhamos uma lista de oito ou dez reivindicacões. O caminho foi aberto pelo CTA. E agora eu pergunto: estamos trilhando a estrada que nos foi oferecida e fazendo jús à briga que mantivemos para poder trilhar por ela? Que eu saiba, uma carta que fosse, nos demos ao trabalho de iniciar. Não nos queixemos, se alguma coisa vai mal (OLIMPICO, 1/9/1959).

Independente das derrotas e das conquistas vale lembrar que as relações institucionais são sempre permeadas por disputas políticas. Desde os anos 80, por exemplo, grande parte das reivindicações estudantis estava ancorada na estruturação do currículo da Escola que pressupunha, também, ampliação dos fóruns de discussão e da participação dos estudantes nestes fóruns. Essa discussão manteve-se na pauta estudantil durante os anos 90 .

A ex-aluna Nair Casagrande assim se refere a esse período:

uma das questões que permeava mas no qual a gente, acredito, não deu conta de acompanhar, de se inserir mais adequadamente ou com maior profundidade foi a discussão em torno também da reestruturação curricular. Nessa discussão que desencadeou agora na fragmentação, no meu ponto de vista, entre bacharel e licenciado. Já na época, naquele período, a gente também acompanhava de certa forma essa discussão da reforma curricular que permanentemente vinha, de certa maneira, passando e havia algumas reestruturações ou pequenas reestruturações em torno de algumas disciplinas $(2005$, p. 4).

Em determinados contextos, a conjuntura propiciava que algumas questões tivessem prioridade. Na década de 80 , o processo de abertura democrática possibilitou um maior contato dos estudantes com questões políticas, inclusive com membros do Diretório Acadêmico sendo militantes de partidos de esquerda. Desta forma, é possível evidenciar algumas das transformações que aconteceram na ESEF desse período como, por exemplo, a não obrigatoriedade

Movimento, Porto Alegre, v. 11, n. 3, p. 201-218, setembro/dezembro de 2005 
do uso de uniformes, as aulas mistas, as alterações curriculares, o fim dos testes práticos para ingresso dos alunos e alunas, entre outras. Nesse momento histórico se dá, também, o início de um maior envolvimento dos estudantes da Escola com o Movimento Nacional de Estudantes de Educação Física.

Descontentamentos, parcerias, provocações, cooperação permearam e permeiam as relações entre os estudantes e a direção da Escola. Em alguns momentos as disputas políticas foram mais intensas, noutros foram dissimuladas compondo um território sempre pleno de tensões visto serem, na maioria das vezes, diferentes as visões, as ações, as demandas e os comprometimentos de um e outro segmento da comunidade esefiana que, entre avanços e recuos, faz sua história cujos estudantes por vezes protagonizam situações por outras são meros espectadores.

\section{Fatos pitorescos: detalhes do cotidiano}

Uma instituição é feita de memórias. Para além dos registros, dos eventos, das instalações, da concretização operacional e acadêmica de sua existência há, ainda, aquelas pequenas histórias que conferem vida e registram detalhes do cotidiano que, na grande maioria das vezes, não figura na oficialidade com a qual se narra a história. Para finalizar esse texto decidimos apresentar dois deles pois foram narrados com entusiasmo, orgulho, traquinagem e emoção.

Na sua entrevista a professora Iula Maria Green Hervé rememora uma pequena transgressão às normas ditadas pelos militares que, de certa forma, orientavam as rotinas da Escola nos seus primórdios. Ao contar sobre a obrigatoriedade do uso de uniforme relata que esses eram feios e também desconfortáveis. Razão pela qual resolveu ousar ao vestir um traje de banho diferente do permitido para as aulas de natação e, como conseqüência, sofreu uma punição:

Uma vez eu fui suspensa porque eu pensei que eu podia botar meu maiô bonito e, não botei o da Escola. Para quê? Porque o maiô da Escola, era um maiô de lã. A gente entrava na água, a saia começava a pesar e a gola ficava quase pela cintura [RISO]. Cada uma com aquele maiô, coisa mais horrível! Então, a gente não botava aquele maiô. Podendo escapar, pronto! Aí, quando eu vi, fui suspensa. Não entra sem ser com o maiô da Escola, era assim..." (HERVÉ, 2005, p. 6).

Durante as primeiras quatro primeiras décadas de existência, a Escola esteve fortemente influenciada pelos militares que não apenas exigiam o uso de uniformes mas, em diferentes ocasiões verifi-

Movimento, Porto Alegre, v. 11, n. 3, p. 201-218, setembro/dezembro de 2005 
cavam detalhadamente se ele estava completo: calção, camisetas, jaquetas, meias, sapatos, etc. Esses uniformes eram utilizados nas aulas realizadas na Escola e também nos eventos cívicos e, nesse particular, o uniforme era diferente e denominado de "uniforme de luxo". Em várias entrevistas são descritos os uniformes e o significado a eles atribuídos e que, grosso modo, relacionavam-se à organização disciplinar dos alunos. Segundo Arno Black, vários professores no início da aula faziam uma inspeção para verificar se o aluno estava devidamente trajado. No seu depoimento relata: "ele chegava e perguntava: está com um calção, deixa eu ver se a cueca é branca, a meia é branca, o tênis é..., era assim, era duríssimo, a questão disciplinar do uniforme era duríssima e se o aluno vinha faltando alguma coisa ele não entrava na sala de aula" $(2005$, p. 3).

Outro fato pitoresco foi lembrado pelo funcionário Cláudio Luiz Garcia que ingressou na ESEF na década de 70. Nesse período lembra de um funcionário a quem chamavam de seu Felício: um negro alto, esguio que cuidava do ginásio. Sempre cuidadoso aos acontecimentos, esse funcionário começou a prestar atenção na rotina de um dos professores da Escola, Bugre Lucena que, todos os dias, corria na pista de atletismo, naquele período feita de carvão. O fato que despertou a curiosidade do seu Felício era que, a cada volta corrida, o professor atirava no chão um pequeno pedaço de pau e sempre no mesmo lugar. Seu Felício observou essa prática por vários dias até que se aproximou do professor e perguntou: "Eu sei que o senhor está cansado e coisa, mas por que o senhor faz a volta na pista e atira um pauzinho, faz e atira um pauzinho?" Indagação essa que obteve a seguinte resposta: "Felício, é que é uma pista pequena e eu marco quantas voltas eu dou por dia. Como a pista é pequena, fica difícil, para mim, guardar o número voltas. Então, cada vez que eu passo aqui, eu atiro um pauzinho e depois eu conto os pauzinhos". Surpreso com a resposta, seu Felício olhou para o professor Bugre Lucena e disse: "Olha só professor, o que é os estudos!" (GARCIA, 2005, p. 7).

Essa e tantas outras situações evidenciam a sutileza através da qual a história de uma instituição se faz. Revelam particularidades, encantamentos, surpresas, desatenções, enfim, um universo de possibilidades que texto algum pode apreender. Pode sim rememorar para que a partir dele outras memórias aflorem, desdobrem-se e transformem-se, por fim, em narrativas históricas.

Movimento, Porto Alegre, v. 11, n. 3, p. 201-218, setembro/dezembro de 2005 


\section{ESEF 65 years: between memories and history}

Abstract: This text is part of the research project named "Prospecting Memories", developed by the team of the Sports Memory Center of ESEF-UFRGS. Through the theoretic-methodological perspective of spoken history it seeks to tell some fragments of the history of the School of Physical Education, 65 years old in May of 2005. For such, there were made 48 interviews with teachers and civil servants of the technical-administrative and academic areas that are still working or have worked in the School. Giving preference for the memory of the interviewed, this text is not configured as an official history of the institution, but essentially as the report of some memories that, grouped in themes, explain some of the life of ESEF, from its foundation until now.

Keywords: School of Physical Education, memories, history.

\section{ESEF 65 años: entre memorias e historias}

Resumen: Este texto hace parte del proyecto de investigación titulado "Garinpando Memorias» desarrollado por el equipo del Centro de Memoria del Deporte de la ESEF-UFRGS. A travez de la perspectiva teórico-metodológica de la historia oral que busca narrar algunos fragmentos de la historia de los 65 años de la Escuela de Educación Física, completados en el mes de mayo de 2005. Para tanto fueron realizadas 48 entrevistas con profesores, funcionarios técnicos- administrativos y academicos que aún están actuando en la Escuela o que ya hicieron parte de sus cuadros. Al privilegiar la memoria de los entrevistados este texto se construye no como una historia oficial de la institución más fundamentalmente, como el relato de algunas memorias que, agrupadas en temas, explicitam un poco de la vida de la ESEF desde su criación hasta los dias actuales.

Palabras-clave: Escuela de Educación Física, memórias, historia. 


\section{Referências}

ALBERTI, Verena. História oral e a experiência do CPDOC. Rio de Janeiro: Centro de Pesquisa e Documentação de História Contemporânea do Brasil, 1989.

BLACK, Arno. Arno Black (depoimento, 2005). Porto Alegre: CENTRO DE MEMÓRIA DO ESPORTE - ESEF/UFRGS, 2005.

BRAUNER, Mário Generosi. Mário Brauner (depoimento, 2004). Porto Alegre: CENTRO DE MEMORIA DO ESPORTE - ESEF/UFRGS, 2005.

CASSEL, Mário César. Mário Cassel (depoimento, 2005). Porto Alegre: CENTRO DE MEMÓRIA DO ESPORTE - ESEF/UFRGS, 2005.

D'AZEVEDO, Helena Alves. Helena D'Azevedo (depoimento, 2005). Porto Alegre: CENTRO DE MEMÓRIA DO ESPORTE - ESEF/UFRGS, 2005.

ECHART, Olga V. K. Olga Echart (depoimento, 2004). Porto Alegre: CENTRO DE MEMÓRIA DO ESPORTE - ESEF/UFRGS, 2005.

FEIX, Eneida. Eneida Feix (depoimento, 2005). Porto Alegre: CENTRO DE MEMÓRIA DO ESPORTE - ESEF/UFRGS, 2005

GARCIA, Cláudio Luiz. Cláudio Garcia (depoimento, 2005). Porto Alegre: CENTRO DE MEMÓRIA DO ESPORTE - ESEF/UFRGS, 2005.

GUTIERREZ, Washington. Histórico. Porto Alegre, 1971. Disponível em http:// www6.ufrgs.br/esef/esef/historico.htm. Acesso em 11 set 2005.

HERVÉ, Iula Maria Green. Iula Hervé (depoimento, 2004). Porto Alegre: CENTRO DE MEMÓRIA DO ESPORTE - ESEF/UFRGS, 2005.

JENKINS, Keith. A História repensada. São Paulo: Contexto, 2004.

KAMINSKI, Leon. Histórias do Movimento Estudantil de Educação Física no Rio Grande do Sul (1956-1964). Porto Alegre: UFRGS, 2005. 68f. Monografia (Licenciatura em Educação Física) Escola de Educação Física, Universidade Federal do ciatura em Educação Fisica)

LICHT, Henrique Felippe Bonet. Henrique Licht (depoimento, 2005). Porto Alegre: CENTRO DE MEMÓRIA DO ESPORTE - ESEF/UFRGS, 2005.

OLIMPICO. Jornal do Diretório Acadêmico Paulo Hollerbach. n 1 , p. 2. Porto Alegre, 01/09/1959.

OLIMPICO. Jornal do Diretório Acadêmico Paulo Hollerbach. n 2, p. 4. Porto Alegre, 20/10/1960.

PACCINI, Quintina. Quintina Paccini (depoimento, 2005). Porto Alegre: CENTRO DE MEMÓRIA DO ESPORTE - ESEF/UFRGS, 2005.

PESAVENTO, Sandra J. História \& História Cultural. Belo Horizonte: Autêntica, 2003.

Movimento, Porto Alegre, v. 11, n. 3, p. 201-218, setembro/dezembro de 2005 
RICHTER, Marlene, César. Marlene Richter (depoimento, 2003). Porto Alegre: CENTRO DE MEMÓRIA DO ESPORTE - ESEF/UFRGS, 2005.

ROUSSO, Henry. A memória não é mais o que era. In: FERREIRA Marieta de M. e AMADO, Janaína. (orgs.) Uso \& Abusos da História Oral. Rio de Janeiro, Fundação Getúlio Vargas, 1996.

SANTIAgo, Diná Pettenuzzo. Diná Santiago (depoimento, 2002). Porto Alegre: CENTRO DE MEMÓRIA DO ESPORTE - ESEF/UFRGS, 2005.

SAUL, Nelson. Nelson Saul (depoimento, 2005). Porto Alegre: CENTRO DE MEMORIA DO ESPORTE - ESEF/UFRGS, 2005.

SOUZA, Walter Frederico de. Walter de Souza (depoimento, 2005). Porto Alegre: CENTRO DE MEMÓRIA DO ESPORTE - ESEF/UFRGS, 2005.

THOMPSON, Paul. A voz do passado: história oral. Rio de Janeiro: Paz e Terra, 1992. 